\title{
Lies, Damned Lies, AVs, Shared Mobility, and Urban Transit Futures
}

\author{
Graham Currie
}

Monash University

\begin{abstract}
"There are three kinds of lies: lies, damned lies, and statistics."
Mark Twain or Benjamin Disraeli (Velleman 2008) ${ }^{1}$
\end{abstract}

\section{Author's Note}

Dear Reader: The editors of the Journal of Public Transportation have given me freedom. They have invited me to put thoughts on a page without the need for pedantic citation and attribution typical of writing in a leading international research journal. I have also been invited to be contemplative and personal, using words and phrases like I think, me, and my. For those of you used to a more formalized, "stodgy" citation full of academic prose, I apologize and ask that you take a deep breath and be calm. Ideas and communication don't always flow well from academic writing, particularly when trying to envision the future.

\section{Introduction}

It seems to me there is a gigantic lot of nonsense discussed about the future of transport and the future of public transport in particular. As a researcher in the field, I find my emotions boiling over. I get angry at blanket statements telling us public transport has no future and it seems to me much of what is talked about regarding transport futures flies in the face of facts and a long history of what knowledge has gleaned about the human condition, economics, cities, and travel. My hope is that readers will see prevailing discourse differently as a result of this paper and get to share my feelings on the matter. Either way, debating the issues is worthwhile and there are new perspectives of much value to debate.

"I wanted to start this piece with the famous Benjamin Disraeli quote on "lies, damned lies"; but in trying to find a source to cite the quote, I found that there is no known attribution to Disraeli and indeed that many think Mark Twain might be the source. Either way, I consider this confusion with ironic awe; what I thought was a foundation stone of thought about "the truth" may indeed be a lie. Perhaps this is a prophetic way to start this paper about transit futures. 
This research paper aims to explore public transport futures but it also aims to challenge and "derail" 2 what current common thinking is on transport futures. It starts with an outline of a rather unusual approach that will use "new words" as a novel medium to explain prevailing thinking. The paper actually begins at "The End" since it is important for readers to understand that prevailing thinking tends to believe that public transport has no future. The new word auto-no-(e)motion is then presented so that readers can assess if a future of autonomous cars is likely; or perhaps "the emperor has no clothes." Next, the word non-o-sharing is introduced to help readers understand what I shall term the shared mobility lie. The paper then closes with a short outline of why public transport is the future of cities and presents the term transit fusion as a new way of explaining how developments in our past will enhance the future of public transport in cities.

\section{Approach}

Thoughts about futures can be very trendy and often fickle. A key part of new trends in thinking is the creation and adoption of new words that take on new meanings that a nontechnical (public) audience finds easier to conceptualize. So autonomous vehicles (AVs) have been associated with automobility and Uber, Lyft, bike share, and car share linked to the term shared mobility. All are widely associated with a highly positive and progressive image, where technological change is said to address the significant problems being faced by cities with a framework focused on replacing the private car with a new, easier to use alternative. A major part of this common narrative is that public transport is old, doesn't work, and its time as an alternative mode is limited. AVs and shared mobility are said to be the progressive alternatives and growth in them is said to be enormous, implying they will soon take over. The author is highly sceptical about this prevailing thinking so is going to adopt the "new word" approach in this paper to reinterpret current thinking. Along the way I shall highlight what I think are lies and what I think are truths, with some technical support for these views.

\section{The End}

It's easy to find detractors of public transit services on planet Earth, not the least of which are day-to-day users having to cope with unreliable services, lack of investment, and crowding. But more recently, discussion around new mobility (another new term) has often seen new approaches to transport as the end of conventional public transport in cities in articles such as the Cato Institute's "The End of Transit and the Beginning of New Mobility" (2014) and Alana Semuels' “The End of Public Transit?" (2016).

It is rare to see any solid factual assessment of practical transport alternatives in this narrative. Rather, it is assumed that public transport is old and not working and that new modes can cost-effectively provide better and cheaper alternatives. There is also occasionally some implication that new modes are held back by old-style thinking about public transport.

${ }^{2}$ Apologies for the pun. 


\section{Auto-no-(e)motion}

DEFINITION: Auto-no-(e)motion is the unscrupulous use of the concept of the autonomous car by technologists to assert that the driverless car will solve all the world's mobility problems, so that we can get rid of urban public transport, which is bad and should have been gotten rid of anyway; good riddance!

There has been a tsunami of interest in popular culture about driverless cars. However, a major thrust of this implies that this future is for the car, that it will make cities more efficient, and even that this is the end of public transport (e.g., Ross 2016).

I think "the emperor has no clothes" is an appropriate phrase to apply to current AV thinking. It is far too early to think these vehicles will dominate travel in cities; in 2016 there were only 180 experimental AVs in California (Stratforma, n.d.) out of a car population of 35.3 million. AVs in common use have some way to go. Indeed, we have no actual working models in general use; rather, trials and tests are the current version of implementation. My own work in Singapore, one of the world's "AV capitals," has a driver in every AV car driving seat "just in case." Of course, it is entirely possible that this technology will not work and not be adopted. This option doesn't seem to be discussed at present, yet we have plenty of new technology failures adorning the history of transport research (e.g., the Segway, Sinclair C5, the Flying Car, Hovercraft, and Maglev, amongst others). The failure of new technologies is actually common. The overselling or hype about the idea is also quite common and has been enshrined in a theoretical framework called the Hype Cycle (Gartner 2016). This is now a website that is updated with the current progress of new ideas through a progression from the oversold hype phase, past the peak of inflated expectations, and down to the trough of disillusionment. Figure 1 shows a montage of the Hype Cycle for the last few years. AVs reached the peak of inflated expectations in 2015 and commenced their path into the trough of disillusionment.

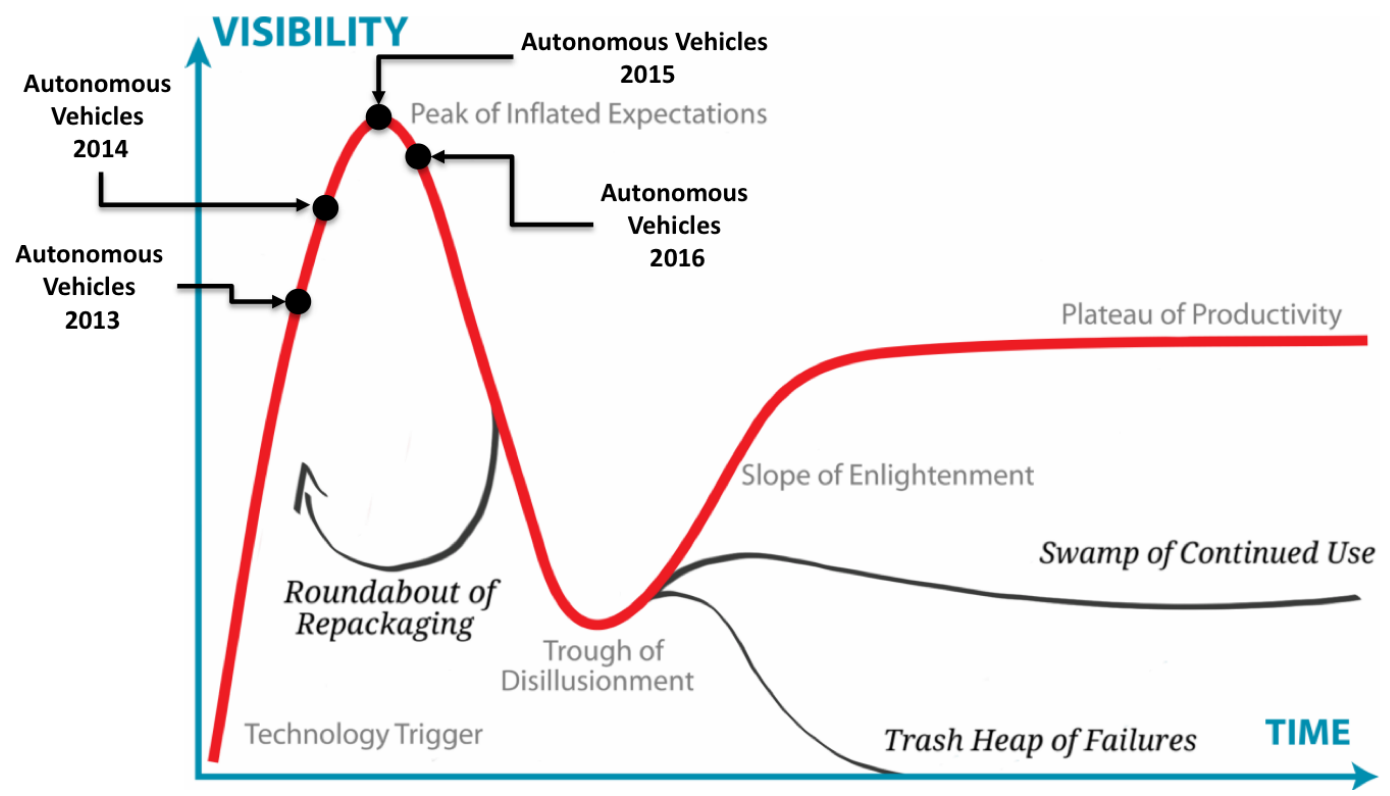

Source: Author's edit based on Gartner (2016)

\section{FIGURE 1.}

Automated Vehicle Technologies and Their Progress along the Hype Curve 
There are some important gaps in the rationale behind how AVs might assist transport problems in cities that point to how public transport might actually be a better solution. The first concerns the capacity problem. There is no clear consensus that fleets of AVs in cities will improve the significant congestion problem facing the world's growing cities. Might they actually make the problem worse? Most recent studies exploring AV futures have found it essential to recognize a role for urban rail in carrying mass volumes of people as part of any scenarios where AVs help cities to work effectively (International Transport Forum 2015). A key part of this discussion is that we need higher occupancy in vehicles to be space efficient in growing congested cities (an imperative I shall come back to). This is clearly a major rationale and advantage of public transport.

There is also an important lie at the heart of the "AVs will take over public transit" argument. That lie concerns the view that public transport is old, too old to be involved in the modern $\mathrm{AV}$ technology trend, and hence car-based AVs will take over. Here is a simple truth: autonomous public transport vehicles dominate land-based passenger travel on planet Earth today and probably will for at the least the next decade. One-quarter of all railways in Asia have no drivers; autonomous trains operate today in Vancouver, Barcelona, London (Victoria Line), AirTrain (JFK NYC), and numerous other cities globally. Between 2006 and 2011, the number of automated train kilometers operated doubled; between 2011 and 2025, the volume of automated train kilometers is expected to increase by over 130\% (UITP 2011). AV trains are not trials, they are not theoretical; they are full systems in passenger operation today. It seems these significant facts are forgotten in the AV car hype. Ironically, a high share of AV trials today involve $\mathrm{AV}$ buses; so how can $\mathrm{AVs}$ be the end of transit when they are already a substantial element of transit?

\section{Non-o-sharing}

DEFINITION: Non-o-sharing is not sharing, but using words to make it look like it is. It is the unscrupulous use of the word sharing by technologists to imply that new mobility modes are good, and it incorrectly asserts they involve lots of shared vehicle occupancy. This is to show they are much better than urban public transport, which is not good and doesn't involve sharing in any good sort of way, and which has to be gotten rid of as soon as possible.

Shared mobility is a term that is widely used now to refer to transport network companies such as Uber and Lyft, bikesharing, and carsharing. Demand responsive transport systems related to these have also been widely said to challenge, and even want to take over, public transit (Free Enterprise 2014; Johnson and Moussako 2014; Brustein 2016).

Shared mobility has many fine features and its progressive, healthy image is well deserved. It demonstrates some of the best applications of new information and communications technologies as a means for making it easier to book and use a transport system. Bike use has many health and fitness advantages and carsharing can actively reduce car ownership 
in cities. However, I argue that the term shared mobility is a lie; I suggest it is used to imply that travel using these modes involves shared vehicle occupancy and is hence equitable and efficient. But to my mind, the lie is that shared mobility doesn't involve sharing of travel within vehicles. In addition, there is a view in current debate that the increasing amount of shared mobility in our cities is providing new solutions to old problems. Yet I argue this is also a lie.

\section{Lie One - Shared Mobility Involves Vehicle Sharing}

The occupancy of a shared bike is almost always one; this means there is no shared occupancy. In data from California, the average occupancy of an Uber vehicle in traffic was found to be 1.66 (SFCTA 2017), accounting for the driver. This implies 0.66 of a passenger per trip, or an empty car in traffic rate of $34 \%$. In effect, $34 \%$ of Uber vehicles on the road are empty. This is not shared occupancy. Even with multiple occupancy of more than one passenger, the degree of sharing is hardly very high. In a study of carsharing also conducted in California, the average occupancy of vehicles was found to be 1.44 (Cervero et al. 2007). In this case, the driver is a valid passenger so there is some degree of occupancy, but it's a long way from the shared occupancy of public transport vehicles. Over 2,000 people can travel in one train; that is real shared mobility! A bus with 50 passengers is also true shared mobility. In effect, most of the new forms of shared mobility don't involve sharing, yet it's shared occupancy we need for the future of growing cities. That's what public transport provides.

\section{Lie Two - Shared Mobility Is Growing, Transforming Shared Vehicle Use in Cities}

It is easy to look at the graphs illustrated in Figure 2 and think that shared mobility will be the way of the future. However, there are a few caveats worth considering before you come to this conclusion. First, the data shown suggests there were around 100,000 shared cars in the world in 2014 (possibly double that in 2017). There were 180,000 Uber drivers in the United States in 2015 and 24,000 shared bikes. While these numbers look large, they actually represent a drop in the ocean of the 1.2 billion car registrations in the world (Davis et al. 2014) and the 264 million cars in the United States (Statista 2017). These shared mobility modes are tiny and the private automobile dominates. 


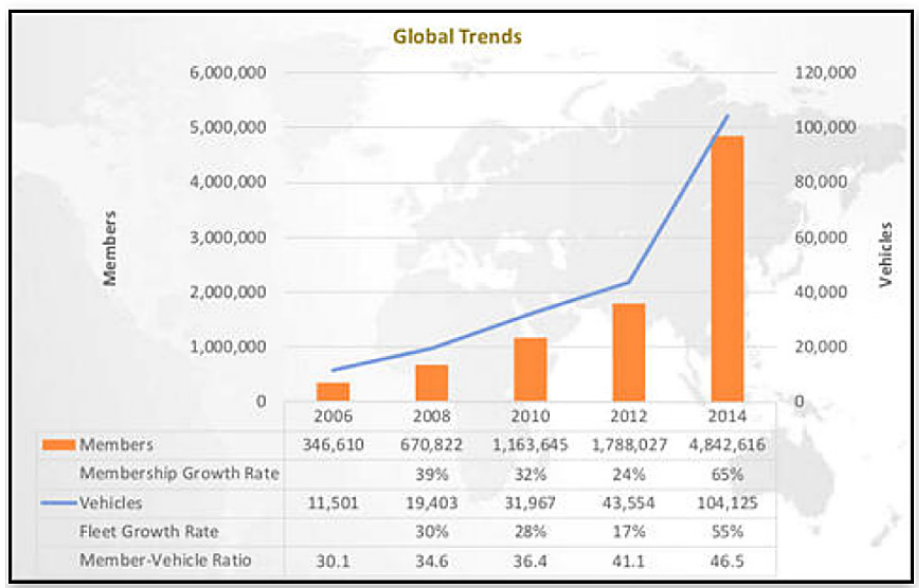

(Shaheen and Cohen 2016)

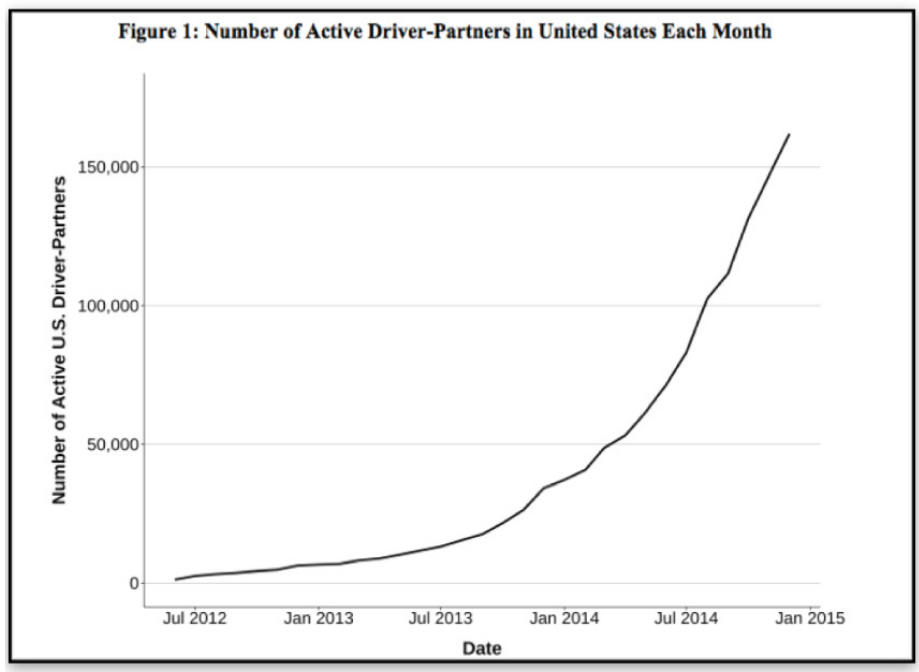

(Hall and Krueger 2015)

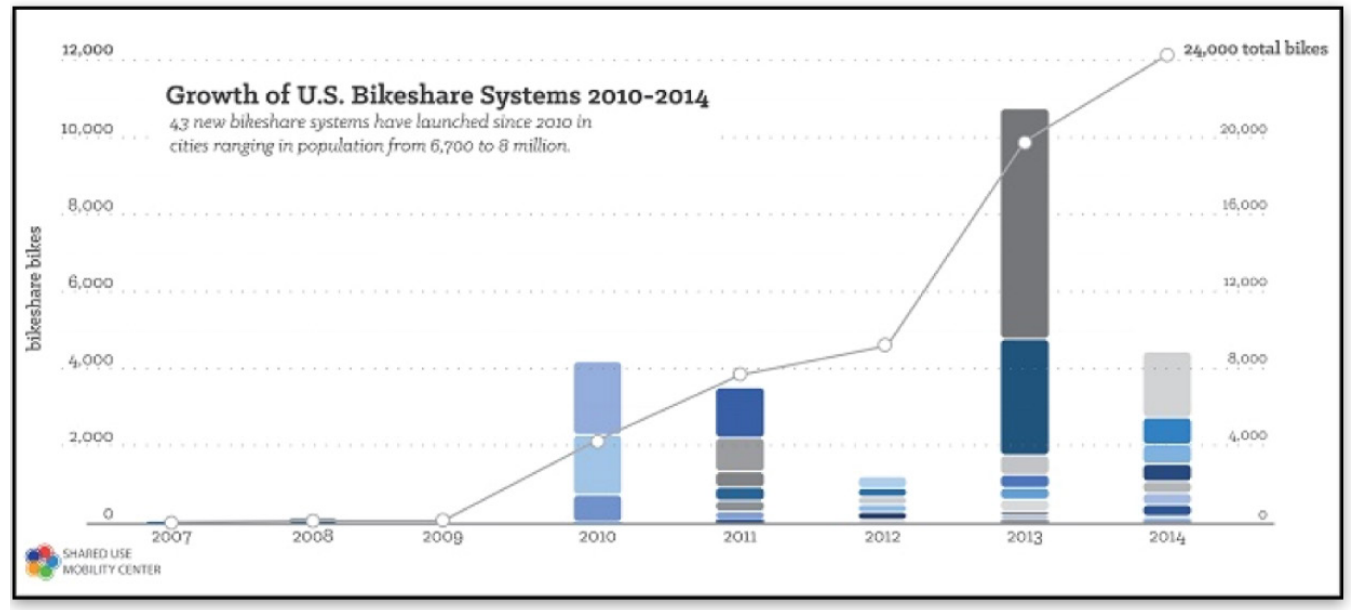

(Shared-Use Mobility Center 2015)

\section{FIGURE 2.}

Data Illustrating that Shared Mobility Is Growing - but Is It? 
Then there is the other truth; car occupancy has been falling dramatically and is still falling. Figure 3 illustrates this problem. It shows car occupancy data for Australian cities over the last 30 years. Commuting vehicle occupancy is now close to 1.0 and is lowest for peak travel (where the need for higher occupancy is largest). World and U.S. trends follow a similar pattern. So, the "inconvenient truth" is that shared mobility is declining, not growing. This is a great tragedy the world needs to address. Pretending that shared mobility is increasing doesn't help.
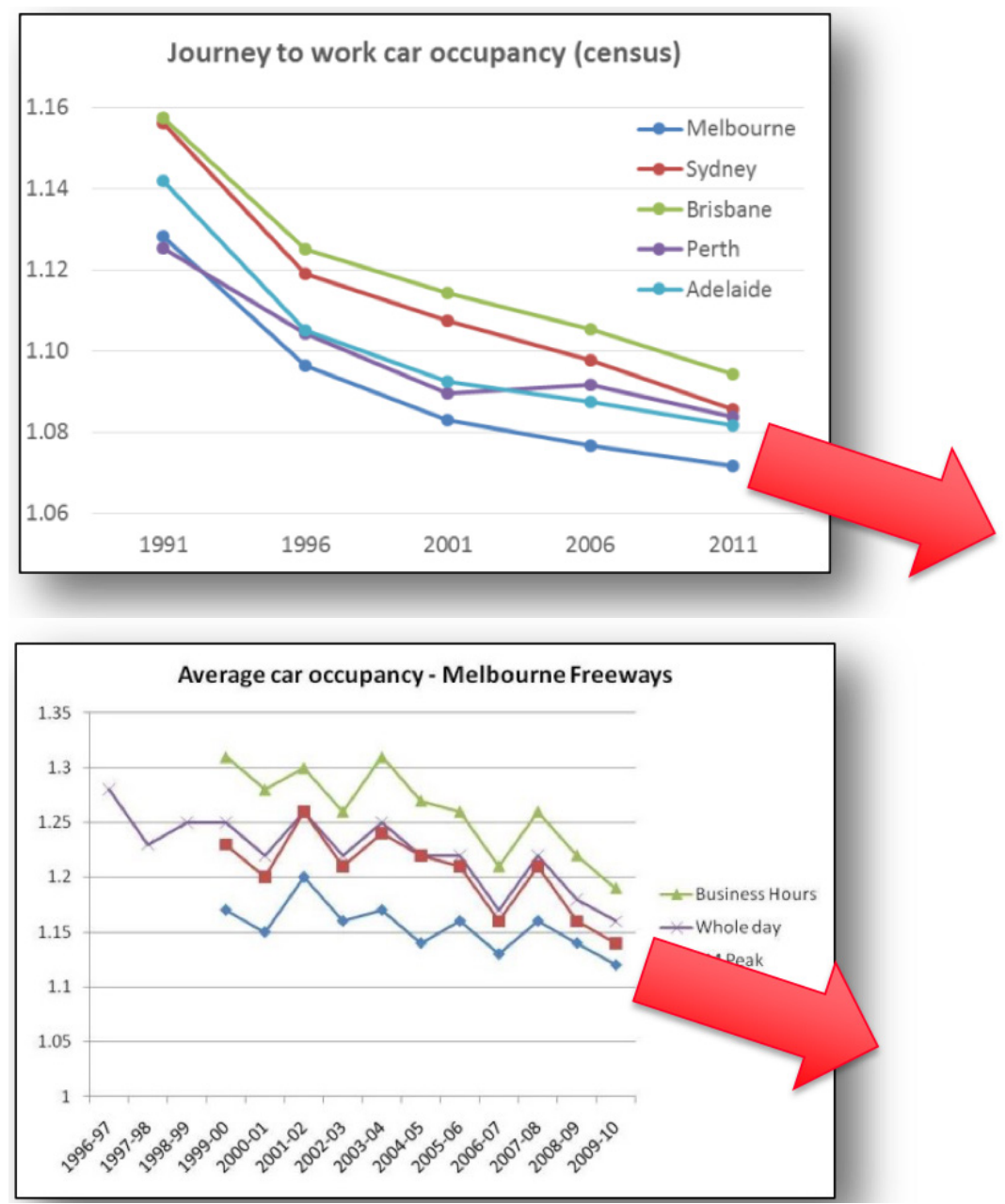

Source: Charting Transport https://chartingtransport.com/tag/car-occupancy/ (last accessed September 2017)

\section{FIGURE 3.}

Car Vehicle Occupancy Over Time (Year) - Sharing Is Declining, Not Growing

The arrows shown in Figure 3 also suggest a future forecast of car occupancy based on historical trends. This might suggest sharing goes below 1.0 , not a likely scenario for current technologies that need a human driver. However, AVs make this outcome entirely feasible as repositioning trips, access, and egress trips become possible without anyone in the vehicle. Does this represent shared mobility? Is a future with AVs including a proportion of vehicles not carrying anyone a realistic solution to high traffic volumes in congested areas? 
There is a last point to consider about $\mathrm{AVs}$ and shared mobility relative to the discourse regarding public transport. In general, public transit's detractors have implied a negative outcome will emerge for transit from these new modes. I would argue that there is quite a lot of evidence that this view is also wrong. In a review of the travel market profile of people who used new shared modes, it was found that public transit was a major aspect of their mobility (Shared-Use Mobility Center 2016). Shared modes were also found to complement and actively increase public transport usage notably because "super-sharers" had lower car ownership, and car ownership reduction is highly related to transit use (Shared-Use Mobility Center 2016). Indeed, a number of strategic reviews of the future of cities are emerging that confirm this view. In an international review of the future of cities, new mobility services were forecast to either increase or maintain existing transit use in all city contexts explored (Bouton et al. 2015). A major feature of these arguments is the fact that new mobility modes might act to address the first/last mile problems faced in accessing public transport modes, thus acting to increase the coverage and attractiveness of transit services.

\section{Why Public Transit?}

Cities now represent humanity's home. In 2007, for the first time, more than half of the world's population were city dwellers (United Nations Population Fund 2007). Between 2000 and 2030, the world's urban population will double. City travel is dominated by the private car (Cosgrove et al. 2009) and is creating a substantial concern for the future of humanity.

- Traffic congestion is now widely recognized as a major and growing urban transportation problem (Cervero 1991; Downs 1992; Arnott and Small 1994). In Australia, congestion costs $\$ 9.4$ billion per year (2005) and is expected to rise to $\$ 20.4$ billion by 2020 (Bureau of Transport and Regional Economics 2007). Based on our current conceptualization of $A V s$, it is entirely likely that they will increase travel since those who cannot drive will be able to use AVs. In addition, declining vehicle occupancy and the fact that AVs can run empty suggest much potential for $A V$ traffic to increase, not decrease, in cities of the future.

- There are significant social and community impacts that car traffic has on urban liveability (Vuchic 1999), including the separation of urban communities by busy roads and impacts on social disadvantage (Rosenbloom 2007). AVs increasing traffic volume will certainly exacerbate this issue, affecting a larger urban population in growing cities.

- Research has established strong links between physical activity and health (British Medical Association 1997; Dora and Phillips 2000). Public transport use involves more physical activity than car travel, suggesting growing health concerns as car use increases (Woodcock et al. 2007). Door-to-door services, implied by AVs and shared mobility modes (other than bike), may reduce walking and physical activity.

Only public transit can address all these concerns since it has the highest vehicle occupancy and the largest capacity to carry large volumes of people efficiently in growing busy cities.

So what is transit's future in this context? My view is that it is highly progressive and big. Transit is far from marginalized by new technologies; it is liberated by them. Continued growth 
in cities is forecast into the future. There is a key imperative to make the future of humanity efficient and effective, where humans share large capacity vehicles moving effectively through tunnels and on raised transitways, and with priority on the streets where the majority of humans live.

\section{Transit Fusion}

DEFINITION: Transit fusion is the adaptation of transit vehicles, infrastructure, and service design to integrate the best features of better performing modes into new transit modes and services to improve overall service performance, attractiveness, and effectiveness outcomes.

Transit fusion has been a trend for some time; it's just not been recognized before. The most obvious recent example is the Bus Rapid Transit movement, where rail-like service features have created "rubber tired railways" including high frequency service, rail-like station designs with platforms and turnstiles, and rail-like rights-of-way using bus vehicles. To some extent, the light rail transit movement was an earlier incarnation of this trend, bringing heavy/commuter rail-like quality of service to suburban, local, and street settings.

I predict transit fusion is a trend that will continue and develop to encompass new mobility modes to address the first/last mile access issue. Examples of this are already in trial today with several transit operators using Transport Network Companies to provide rail feeder functions. Shared bike schemes are the backbone of rail access in many cities in China today (and have been in the Netherlands for some time). Another more fundamental and potentially groundbreaking variant emerging from transit fusion is how transit authorities might transform into shared mobility agencies. Already some German rail operators have started to operate carsharing schemes. They have found that transit-reliant passengers occasionally need cars and where better to provide them than at the stations they use every day. An interesting thought few have considered: would transit agencies not be an obvious institution to run and maintain fleets of $A V s$ should this type of future eventuate? They already operate and maintain large fleets covering all metropolitan geographies. Who else is better placed, and has depots in place, to run $A V s$ in these contexts into the future?

Overall, my version of transit futures sees substantial growth in the scale and worldwide distribution of services as cities continue to grow and require greater efficiency and effectiveness from the shared occupancy of vehicles. There are some important lies implied in the prevailing discourse on $A V s$ and shared mobility suggesting transit futures are limited as a result. The truth is that transit systems are the only option available for shared occupancy at the volume needed and the quality provided that can meet the needs of large and growing cities. New shared mobility and $A V$ technologies enhance these transit futures, reducing transit costs and increasing transit attractiveness. A critical failing of the contemporary narrative on AVs and shared mobility is the lack of an understanding of the need to increase vehicle occupancy. There is a significant global trend toward reduced occupancy and personalized sole person mobility driven by human behavior and preferences. These are the intractable barriers to effective AV and shared mobility use, though public transit systems have shown much success in this area. 
So what form will public transit futures take? I suggest mass transit using rail and bus/light rapid transit will be a necessary requirement. Segregated rights-of-way for mass volume modes are needed. Simple calculations on volume illustrate the need for mass transit shared occupancy of modes, rather than privatized single person vehicles, as a better use of limited space. Transit fusion will ensure the most appropriate design, but does require a move away from conventional transit single mode thinking.

So will this vision of transit futures happen in all contexts? Almost certainly not. Central downtowns and now inner and middle suburbs in growing cities will find mass transit compelling and essential. However, small towns and outer suburban, low-density areas will struggle with low productivity bus services and the continued need for substantial subsidy. Can new mobility modes act to replace transit in these contexts? Possibly, but this may just be wishful thinking. There is a remarkably strong correlation between the availability of new mobility modes and higher density central areas. However, in areas of lower density, there are low levels of demand, dispersed trip ends, and long trip lengths. All modes struggle to provide quality service in these contexts and I have seen no evidence yet that new mobility services can do better in the long term than existing basic bus services. Perhaps here a bus-based AV service can be more productive. Some $70 \%$ of bus costs are drivers, so theoretically, costs can be reduced and service levels enhanced with an automated vehicle bus service. What about demand responsive transit (DRT) bus services? Certainly, DRT buses have been promoted in many new mobility services. One problem with this suggestion is the very long history of almost complete failure in DRT based bus services for the last 50 years. We have seen no glowing long-term survival of these schemes as an alternative to suburban buses to date. More recently, perhaps as expected, new mobility DRTs such as Bridj have failed.

The future is never fully knowable, but the way we think about the future is often questionable. No one fully understands what will happen to our urban futures, but as long as cities and urban densities grow, public transit is likely to be at the heart of successful city futures forever.

\section{References}

Arnott, R. and K. Small. 1994. "The Economics of Traffic Congestion." American Scientist, 82(5): 446-455.

Bouton, S., S. Knupfer, I. Mihov, and S. Swartz. 2015. "Urban Mobility at a Tipping Point." McKinsey \& Company. https://www.mckinsey.com/business-functions/sustainability-andresource-productivity/our-insights/urban-mobility-at-a-tipping-point

British Medical Association. 1997. Road transport and health. London: BMA Professional Division Publications.

Brustein, J. 2016. "Uber and Lyft want to replace public buses." Chicago Tribune. http://www.chicagotribune.com/business/ct-uber-lyft-public-transit-20160815-story.html

Bureau of Transport and Regional Economics. 2007. Estimating urban traffic and congestion cost trends for Australian cities - Working Paper No 71. Canberra, Australia: Department of Transport and Regional Services. 
Cato Institute. 2014. "The End of Transit and the Beginning of the New Mobility: Policy Implications of Self-Driving Cars." https://www.cato.org/events/end-transit-beginning-newmobility-policy-implications-self-driving-cars

Cervero, R. 1991. "Congestion, Growth, and Public Choices." Berkeley Planning Journal, 3(2): 55-75. Berkeley, CA: University of California Transportation Center.

Cervero, R., A. Golub, and B. Nee. 2007. "City CarShare: Longer-Term Travel Demand and Car Ownership Impacts." Transportation Research Record: Journal of the Transportation Research Board, 1992: 70-80. doi: 10.3141/1992-09.

Cosgrove, D., D. Gargett, and D. Mitchell. 2009. Urban passenger transport: how people move about in Australian cities - Information Sheet 31. Canberra, Australia: Bureau of Infrastructure, Transport and Regional Economics.

Davis, S., S.W. Diegel, and R. Boundy. 2014. Transportation Energy Data Book: Edition 33. Oak Ridge, TN: Oak Ridge National Laboratory.

Dora, C. and M. Phillips, Eds. 2000. Transport, environment and health - WHO Regional Publications, European Series, No. 89. World Health Organization Regional Office for Europe.

Downs, A. 1992. Stuck in Traffic: Coping with Peak-Hour Traffic Congestion. Washington, DC: The Brookings Institution.

Free Enterprise. 2014. "Bridj: A Bridge to a New Kind of Mass Transit." Washington, DC: U.S. Chamber of Commerce.

Gartner. 2016. "Gartner's 2016 Hype Cycle for Emerging Technologies Identifies Three Key Trends That Organizations Must Track to Gain Competitive Advantage." Press Release. http://www.gartner.com/newsroom/id/3412017

Hall, J. and A. Krueger. 2015. An Analysis of the Labor Market for Uber's Driver-Partners in the United States. IRS Working Paper \#587. Princeton University. http://arks.princeton.edu/ ark:/88435/dsp010z708z67d

International Transport Forum. 2015. Urban Mobility System Upgrade - How shared self-driving cars could change city traffic. Corporate Partnership Board Report. OECD.

Johnson, B. and A. Moussako. 2014. "Pop-up bus service looks to reinvent mass transit." Marketplace. American Public Media. https://www.marketplace.org/2014/07/03/tech/popbus-service-looks-reinvent-mass-transit

Rosenbloom, S. 2007. "Lessons for Australia from the US: an Amercian looks at transportation and social exclusion." No way to go: transport and social disadvantage in Australian communities, 3. G. Currie, ed. Clayton, Vic: Monash University ePress.

Ross, D. 2016. "Driverless cars could make mass transit obsolete." mynorthwest.com. Kiro Radio. http://mynorthwest.com/433989/driverless-cars-mass-transit/

Semuels, A. 2016. "The End of Public Transit?" The Atlantic. https://www.theatlantic.com/ business/archive/2016/10/public-transportation-uber-chariot/505658/ 
SFCTA. 2017. TNC's Today - A Profile of San Francisco Transportation Network Company Activity. Draft Report. San Francisco, CA: San Francisco County Transportation Authority.

Shaheen, S. and A. Cohen. 2016. Innovative Mobility Carsharing Outlook: Carsharing Market Overview, Analysis, and Trends, Winter 2016. Transportation Sustainability Research Center, University of California, Berkeley.

Shared-Use Mobility Center. 2015. "What Bikesharing's Growth Means for Shared Mobility." Bikesharing News. http://sharedusemobilitycenter.org/news/what-bikesharings-growthmeans-for-shared-mobility/

Shared-Use Mobility Center. 2016. Shared Mobility and the Transformation of Public Transit. TCRP J-11/TASK 21, Transit Cooperative Research Program and American Public Transportation Association.

Statista. 2017. "Number of vehicles registered in the United States from 1990 to 2015 (in 1,000s)." https://www.statista.com/statistics/183505/number-of-vehicles-in-the-unitedstates-since-1990/

Stratforma Consulting Limited (blog). "The Digital Driving Age: A Bumpy Road Ahead?" http:// www.stratforma.com/the-digital-driving-age-a-bumpy-road-ahead/

UITP. 2011. Metro Automation Facts, Figures and Trends. Press Kit. Brussells, Belgium: Union Internationale des Transports Publics.

United Nations Population Fund. 2007. State of World Population 2007 - Unleashing the Potential of Urban Growth. New York: United Nations Population Fund.

Velleman, P. 2008. "Truth, Damn Truth, and Statistics." Journal of Statistics Education, 16(2).

Vuchic, V. 1999. Transportation for Livable Cities. New Brunswick, NJ: Rutgers Center for Urban Policy Research.

Woodcock, J., D. Banister, P. Edwards, A. Prentice, and I. Roberts. 2007. "Energy and Health 3: Energy and transport." Lancet, 370: 1078-88. doi:10.1016/S0140-6736(07)61254-9.

\section{About the Author}

Graham CURRIE, Ph.D., is a professor of Public Transport at Monash University and an international public transport research leader and policy advisor with over 30 years of experience. He is founder and director of the Public Transport Research Group (PTRG) at Monash University, which in 2015 was identified as one of the top three research groups in the world by an independent European review of the field. PTRG aims to improve transit research for all concerned with cities and maintains the World Transit Research website (www.worldtransitresearch.info) to improve access to quality research. Professor Currie has published extensively in leading international peer research journals in this field and won numerous awards for his papers. He specializes in research on public transport markets, route and network design in transit, transit futures, and the social and economic benefits of urban transit. 